International Journal of Current Advanced Research

ISSN: O: 2319-6475, ISSN: P: 2319 - 6505, Impact Factor: SJIF: 5.995

Available Online at www.journalijcar.org

Volume 6; Issue 3; March 2017; Page No. 2811-2812

DOI: http://dx.doi.org/10.24327/ijcar.2017.2812.0112

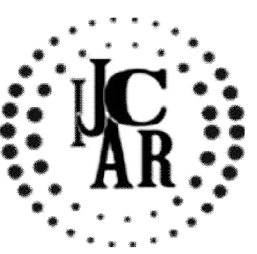

Research Article

\title{
DETERMINATION OF SEX BY USING THE LENGTH OF ADULT FEMUR BONES
}

\section{R.Jagadish Rajkumaar and Thenmozhi M.S.}

Department Anatomy Saveetha dental college

\section{A R T I C L E I N F O}

\section{Article History:}

Received $10^{\text {th }}$ December, 2016

Received in revised form $26^{\text {th }}$ January, 2017

Accepted $11^{\text {th }}$ February, 2017

Published online $28^{\text {th }}$ March, 2017

\section{Key words:}

Length of femur Head of femur, Femoral condyle, Medico Legal Investigations. \begin{abstract}
A B S T R A C T
Topic: Determination of sex by using the length of femur in Tamilnadu.

Aim : To do the study of determination of sex using dry femur bones.

Objective : To find the gender by identifying the length of femur bone.

Background : Identification of sex from skeleton is an important demographic assessment in medico legal investigations. Length of femur is an important and reliable skeletal element for sex determination. The present study aims at obtaining results from the length of femur. The length of femur which is taken as the maximum vertical distance between the upper end of head of femur and lowest point on femoral Condyle.
\end{abstract}

Reason: This will be helpful in solving forensic problem to some extent.

Copyright $@ 2017$ R.Jagadish Rajkumaar and Thenmozhi M.S. This is an open access article distributed under the Creative Commons Attribution License, which permits unrestricted use, distribution, and reproduction in any medium, provided the original work is properly cited.

\section{INTRODUCTION}

The femur is the only bone located within the human thigh. It is both the longest and the strongest bone in the human body, extending from the hip to the knee. The femur is the longest and, by most measures, the strongest bone in the human body. Its length on average is $26.74 \%$ of a person's height a ratio found in both men and women and most ethnic groups with only restricted variation, [2] and is useful in anthropology because it offers a basis for a reasonable estimate of a subject's height from an incomplete skeleton. [1] Sex determination of the unknown skeletal material is one of the most vital questions required to be answered with $100 \%$ accuracy in [3] medico legal cases as a part of establishing identity of the diseased from skeletal remains. Therefore in the present study femur bones were studied for the determination of sex in the populations of South India.

\section{MATERIALS AND METHOD}

The present study was Carried out Using 30 dry femur bones of the adult males and females from the department of anatomy SaveethaDentalCollege. An Inch tape was utilized to measure maximum length of femur which is taken as the maximum vertical distance between the upper end of head of femur and lowest point on femoral Condyle.

\section{RESULT}

The values of the mean maximum length in male femora in

\section{*Corresponding author: R.Jagadish Rajkumaar}

Department Anatomy Saveetha dental college south India was 44.25 (right) and 43.35 (left) and that in female $41.8 \mathrm{~mm}$ (right) and $42.25 \mathrm{~mm}$ (left). The mean values obtained were in accordance with that of the values calculated from various other researchers which can be seen in the tables $\mathrm{A}$ and $\mathrm{B}$ given below.

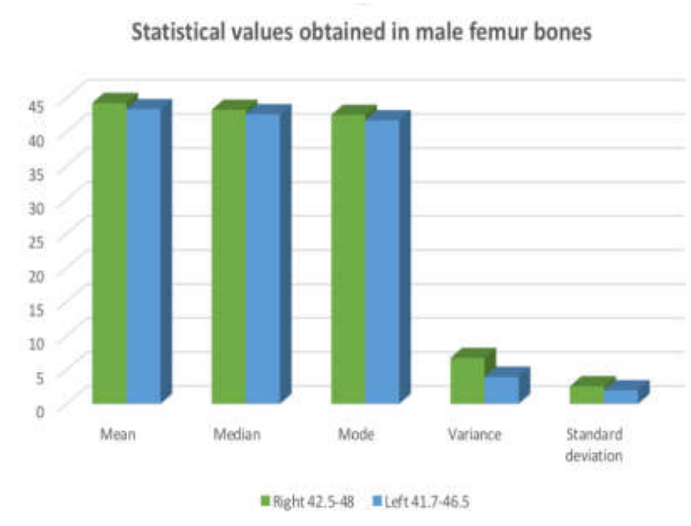

Statistical values obtained in female femur bones

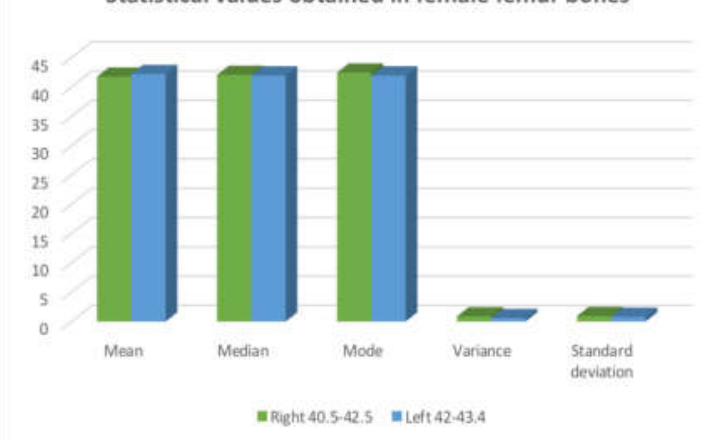


TABLE: A Comparison of Maximum femoral length in MALES

\begin{tabular}{|c|c|c|c|}
\hline Population and Study & \multicolumn{3}{|c|}{ MALES } \\
\hline & Mean & SD & $\%$ Identi \\
\hline Di Bernardo and Taylor Am. black & 475 & 31.4 & $\cdot$ \\
\hline Dittrick J and Suchey M, California & 420.6 & 17.2 & $79.55 \%$ \\
\hline J. Schan and Shihhai Chinese & 400.97 & 19.71 & - \\
\hline J. Schan and Steyn, South African Whites & 469.68 & 27.97 & - \\
\hline King CA etal Thai & 429.4 & 21.38 & - \\
\hline Purkait and Chandra, India & 451.47 & 23.38 & $84.50 \%$ \\
\hline Present Study & Right=450.82 & 23.84 & $13.33 \%$ \\
\hline & Left=452.37 & 22.63 & $7.24 \%$ \\
\hline
\end{tabular}

TABLE: $B$ Comparison of Maximum femoral length in FEMALES

\begin{tabular}{|c|c|c|c|}
\hline Population and Study & \multicolumn{3}{|c}{ FEMALES } \\
\hline & Mean & SD & $\%$ Identi \\
\hline Di Bernardo and Taylor Am. black & 443 & 23.6 & $71.00 \%$ \\
\hline Dittrick J and Suchey M, California & 420.6 & 17.2 & $79.55 \%$ \\
\hline J. Schan and Shihai Chinese & 400.97 & 19.71 & - \\
\hline J. Schan and Steyn, South African Whites & 469.65 & 20.65 & - \\
\hline King CA etal Thai & 397 & 19.6 & - \\
\hline Purkait and Chandra, Indian & 403.69 & 17.79 & $91.30 \%$ \\
\hline & 417.48 & 19.74 & $4.35 \%$ \\
\hline Present Study & Right=416.49 & 19.83 & $4.37 \%$ \\
\hline & Left $=420.43$ & 21.38 & $8 \%$ \\
\hline
\end{tabular}

\section{CONCLUSION}

To conclude the result of the present study further confirms the views of earlier workers that population specific studies in this aspect are mandatory and beneficial for sex determination.The results of the present study will help in accurate diagnosis of sex from both complete and fragmentary femora from South Indian population and thus constitutes an important tool for forensic experts.

\section{DISCUSSIONS}

Sex determination from long bones or their fragments is required as it is a possible identity. The [5] forensic experts often face problems with poorly preserved or fragmented bones which makes their identification complicated [4] due to the tubular structure of the bones they are preserved better than the normal bones. Thus the data collected from the femur bones was beneficial.In the past [8] the percentage accuracy of males was less compared to that of the females it the specificity was higher in case of males.this could be due to the more [9] variable lifestyle and the difference in the labour of both these sexes [10] which can be a determining factorof the length of the femur bones.

\section{Statistical for maximum femoral length}

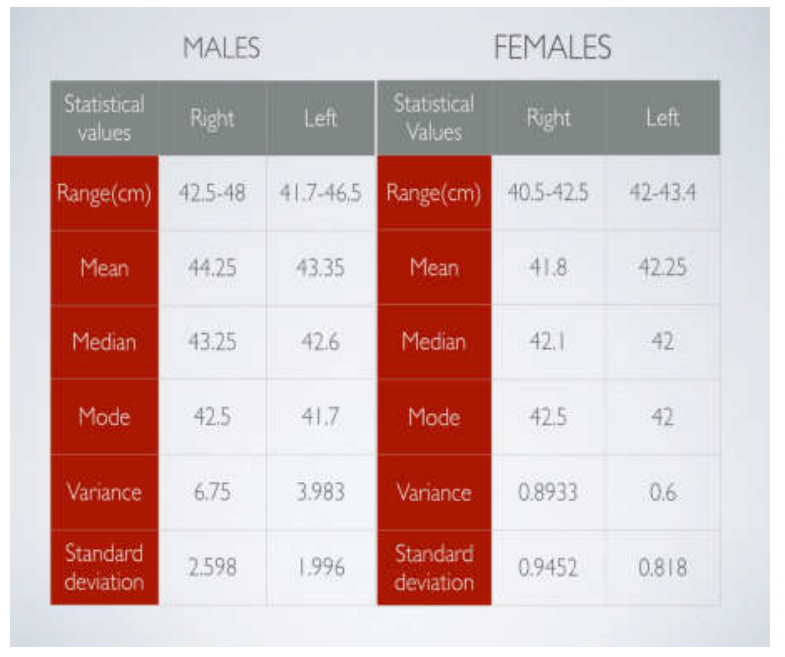

[7] However the effect of the environment and the genetical factors are also to be considered. Although all the measurements were more in Males as compared to that of the females in conclusion of the present study fulfils the need to update Standards that can be used in determining sex in the identification process.

\section{References}

1. Rajeshwari S. Bhosale1, Dr. B. R. Zambare2 IOSR Journal of Dental and Medical Sciences (JDMS) ISSN: 2279-0853, ISBN: 2279-0861. Volume 3, Issue 4 (Jan. - Feb. 2013), PP 01-03 www.iosrjournals.org

2. ŽeljanaBašić, IvanaAnterić, [...], and ŠimunAnđelinović Sex determination in skeletal remains from the medieval Eastern Adriatic coastdiscriminant function analysis of humeri.

3. Dittrick J. and Suchey J. M., Sex determination of prehistoric central California skeleton remains using discriminant analysis of the femur and humerus, American Journal of Physical Anthropology 1986, 70: 3-9.

4. Iscan M.Y. and Shihai D., Sexual Dimorphism in the Chinese Femur. Forensic Science International June 1995, 74(1-2),79-87.

5. Steyn M. and Iscan M. Y., Sex determination from the femur and tibia in South African whites, Forensic Science International 1997,90: 111-119.

6. King C.A., Iscan M. Y. and Loth S.R., Metric and comparative analysis of sexual dimorphism in the Thai Femur. Journal of Forensic Science 1998, 43(5): 954-958.

7. Leelavathy N, Rajangam S, Janakiram S., Thomas IM, Sexing Of The Femora. Indian Journal of Anatomical. Society of India, 2000,49 (1) 17-20.

8. Purkait R. and Chandra H., Sexual Dimorphism in Femora: An Indian Study. Forensic Science Communications 2002 July, 4(3): 1-6.

9. Pal G.P., Reliability of criteria used for sexing of hip bone. Journal of Anatomical Society of India. 2004, 53

10. Wu L. Sex Determination of Chinese Femur by Discriminant Function: J Forensic Sci. Sep 1989; 34(5):1222-7. 